\title{
Espécies novas de Calliini e Falsamblesthiini (Coleoptera, Cerambycidae, Lamiinae) da Região Neotropical
}

\author{
Maria Helena M. Galileo ${ }^{1,3}$ \& Ubirajara R. Martins s,3 $^{2,3}$
}

${ }^{1}$ Museu de Ciências Naturais, Fundação Zoobotânica do Rio Grande do Sul. Caixa Postal 1188, 90001-970 Porto Alegre-RS, Brasil. ${ }^{2}$ Museu de Zoologia, Universidade de São Paulo. Caixa Postal 42494, 04218-970 São Paulo-SP, Brasil.

${ }^{3}$ Pesquisador do CNPq.

\begin{abstract}
New species of Calliini and Falsamblesthiini (Coleoptera, Cerambycidae, Lamiinae) of the Neotropical region. The following taxa are described: Calliini - Drycothaea gaucha sp. nov. from Rio Grande do Sul, Brazil; Callia metallica sp. nov. from Sucumbios, Ecuador; Falsamblesthiini - Nyctonympha boyacana sp. nov. from Colombia; Bactriola achira sp. nov., and Bactriola antennata sp. nov. both from Santa Cruz, Bolivia.

KEYWORDS. Bactriola, Callia, Drycothaea, Nyctonympha, taxonomy.

RESUMO. Espécies novas de Calliini e Falsamblesthiini (Coleoptera, Cerambycidae, Lamiinae) da Região Neotropical. As seguintes novas espécies são descritas em Callini: Drycothaea gaucha sp. nov. do Rio Grande do Sul, Brasil; Callia metallica sp. nov. de Sucumbios, Equador; em Falsamblesthiini: Nyctonympha boyacana sp. nov. da Colômbia; Bactriola achira sp. nov. e Bactriola antennata sp. nov. ambas de Santa Cruz, Bolívia.
\end{abstract}

PALAVRAS-CHAVE. Bactriola, Callia, Drycothaea, Nyctonympha, taxonomia.

Acrescentam-se duas novas espécies à tribo Calliini, uma em Drycothaea Thomson, 1868 e uma em Callia AudinetServille, 1835.

O gênero Drycothaea está constituído hoje por 21 espécies, 19 estão arroladas por (Monné, 2005), uma descrita por Lingafelter \& Nearns (2007) e uma que descrevemos a seguir. Onze espécies ocorrem no México, América Central (Continental e Insular) e 10 na América do Sul. Martins \& Galileo (1990) apresentaram uma chave para as cinco espécies sul-americanas então conhecidas. Tavakilian (1991) constatou, após exame dos exemplares-tipos, que Breuning $(1943,1974)$ descreveu duas espécies em gêneros na tribo Desmiphorini (com garras tarsais simples): Estoloides Breuning, 1940 e Trichestola Breuning, 1950 e providenciou as transferências para Drycothaea: D. angustifrons (Breuning, 1943) e D. mexicana (Breuning, 1974).

Galileo \& Martins (1991) propuseram a sinonímia dos gêneros Drycothaea, Estolopsis Breuning, 1940 e Guyanestola Breuning, 1961 (estes descritos em Desmiphorini) e, conseqüentemente, as espécies-tipo foram transferidas para Drycothaea: D. ochreoscutelaris e D. macrophthalma.

Tavakilian (1997) estabeleceu sinônimos, nova combinação e propôs nome novo para quatro espécies de Drycothaea: $D$. angustifrons $=$ Guyanestola macrophthalma Breuning, 1961; D. brasiliensis (Breuning, 1974) $=$ D. marmorata Martins \& Galileo, 1990; D. truncatipennis Tavakilian, 1997 (nome novo para Estola stictica Breuning, 1942 non Bates, 1881); D. turrialbae (Breuning, 1943) transferida do gênero Estoloides.

As espécies de Drycothaea estão arroladas em Monné \& Hovore (2006).

No gênero Callia, conhecem-se 33 espécies (Monné 2005) das quais três estão assinaladas para a América Central.

Zajciw (1958) apresentou uma chave para as espécies brasileiras de Callia que, na ocasião, envolvia dois subgêneros: Callia s. str. e Mimolaia Bates, 1881. As espécies incluídas foram 16, uma em Mimolaia e 15 em Callia. Mimolaia foi elevado a status genérico por Galileo \& Martins (1991). Nesse mesmo trabalho foi inserida uma chave para as espécies de Callia então com 23 espécies. Os mesmos autores (2002) descreveram oito espécies e fizeram nova chave para as espécies, contando na época com 32 espécies.

Em Falsamblesthiini são descritas três espécies, uma em Nyctonympha Thomson, 1868 e duas em Bactriola Bates, 1885. Os dois gêneros tiveram publicadas chaves para o reconhecimento das espécies, respectivamente por Martins \& Galileo (1989e 1992).

As abreviaturas no texto correspondem às coleções: Fernando Fernández, Instituto de Investigaciones de Recursos Biológicos “Alexander von Humboldt", Villa de Leyva (IAHC); James E. Wappes, American Coleoptera Museum, San Antonio (ACMS) e Museo Noel Kempff Mercado, Santa Cruz (MNKM); Museu de Ciências Naturais, Fundação Zoobotânica do Rio Grande do Sul (MCNZ) e Museu de Zoologia, Universidade de São Paulo, São Paulo (MZSP).

\section{Calliini \\ Drycothaea gaucha sp. nov.} (Fig. 1)

Tegumento avermelhado. Cabeça coberta por pubescência amarelada. Lobos oculares inferiores com o quádruplo do comprimento das genas. Distância entre os lobos oculares superiores menor que a largura de um lobo. Escapo com tegumento mais escuro que o dos demais antenômeros. Flagelômeros indistintamente anelados de branco na base. Antenômero III subigual em comprimento ao IV. Antenas das 
fêmeas atingem o ápice dos élitros na ponta do antenômero $\mathrm{X}$ e, dos machos, no meio do antenômero IX.

Protórax revestido por pubescência amarelada. Espinho lateral do protórax, curto. Distância entre os pontos no meio do pronoto igual ao diâmetro de um ponto. Tubérculo do mesosterno simples. Lados do metasterno lisos.

Élitros revestidos por pubescência amarelada; pontos esparsos no meio do dorso, não organizado em fileiras; extremidades elitrais arredondadas.

Urosternitos revestidos por pubescência amarelada com evidente pontuação contrastante. Fêmures com pubescência branca e pontos contrastantes e esparsos.

Dimensões, em mm, machos/fêmeas respectivamente. Comprimento total, 10,0-12,3/10,4-11,0; comprimento do protórax, 1,9-2,2/2,0-2,2; maior largura do protórax, 2,4-2,9/2,32,5; comprimento do élitro, 7,5-9,2/7,7-8,2; largura umeral, 3,2$3,7 / 3,1-3,7$.

Material-tipo. Holótipo macho, BRASIL, Rio Grande do Sul: Pelotas, XI.1951, E. N. Kellersvig-Waering col. (ACMS). Parátipos, macho e 2 fêmeas com os mesmos dados do holótipo (MZSP, MCNZ, ACMS)

Discussão. Drycothaea gaucha sp. nov. estende a distribuição do gênero para o Brasil meridional e até o momento apenas duas espécies eram conhecidas da Mata Atlântica: $D$. viridescens (Buquet, 1857) e D. truncatipennis Tavakilian, 1997. Difere de $D$. viridescens pela pubescência corporal amarelada e pontos elitrais não organizados em fileiras. De $D$. truncatipennis, distingue-se pelo ápice dos élitros individualmente arredondados e a pubescência elitral não entremeada de branco.

Em D. viridescens os élitros são revestidos por pubescência acinzentada com reflexos esverdeados, em alguns exemplares os pontos são enfileirados. Em D. truncatipennis os ápices dos élitros são obliquamente truncados e a pubescência elitral é entremeada por pequenas manchas de pubescência branca principalmente na metade apical.

Etimologia. Epíteto alusivo à procedência no sul do Brasil.

\section{Callia metallica sp. nov.}

(Fig. 2)

Tegumento preto: cabeça, antenas até o antenômero VII, protórax, face ventral do corpo, tíbias e tarsos. Antenômeros VIII a XI com tegumento branco. Fêmures alaranjados com o ápice preto. Élitros azul-violáceos com reflexos metálicos.

Fronte e vértice com pontos profundos e isolados e pubescência branca e indistinta. Antenas atingem a declividade apical dos élitros. Protórax com espinho lateral pequeno. Pronoto densamente pontuado, praticamente sem pubescência. Élitros densa e profundamente pontuados, principalmente na metade anterior. Lados do metasterno com pontos grandes e profundos.

Dimensões, em mm, holótipo macho. Comprimento total, 6,0; comprimento do protórax, 1,2; maior largura do protórax, 1,6; comprimento do élitro, 4,3; largura umeral, 1,9.

Material-tipo. Holótipo macho, EQUADOR, Sucumbios: San Rafael falls $(1100 \mathrm{~m})$, 5-6.VIII.1998, W.Opitz col. (ACMS).
Discussão. Callia metallica sp. nov. assemelha-se a $C$. gallegoi Galileo \& Martins, 1991 pelas antenas com antenômeros VIII-XI brancos, pelo protórax preto e pelos élitros azul-violáceos com reflexos metálicos. Difere pelos fêmures alaranjados com ponta preta, pela fronte e pronoto pontuados.

Callia metallica sp. nov. pelos fêmures alaranjados também é semelhante a C. ardodi Belon, 1903 e C. tristis Galileo \& Martins, 2002. Difere de C. argodi pelo pronoto unicolor, antenômero VIII branco e élitros com brilho metálico. Em $C$. argodi, o pronoto tem mancha irregular de tegumento avermelhado, o antenômero VIII é preto e os élitros não tem reflexos metálicos. Difere de C. tristis pelo aspecto mais compacto, antenômero VIII branco; em C. tristis o corpo é alongado e o antenômero VIII é preto.

Etimologia. Latim, metallicus $=$ metálico; referente aos reflexos metálicos do tegumento dos élitros.

\section{Falsamblesthiini \\ Nyctonympha boyacana sp. nov.}

(Fig. 3)

Tegumento avermelhado coberto por pubescência esbranquiçada. Fronte e vértice regular e fortemente pontuados. Lobos oculares superiores com seis fileiras de omatídios, tão distantes entre si quanto o dobro da largura de um lobo (macho) ou mais distantes entre si do que a largura de um lobo (fêmea). Antenas atingem o ápice do élitro no meio do antenômero X. Escapo com pontos contrastantes. Antenômero III e IV avermelhados e unicolores. Base dos antenômeros V a XI com tegumento esbranquiçado.

Pronoto densa e uniformemente pontuado; nos lados, com espinho pouco atrás do meio. Região central dos élitros com pontos enfileirados, principalmente ao lado da sutura; alguns desses pontos mais escurecidos; no lado externo do terço apical, pontuação mais esparsa. Extremidades cortadas em curva com espinho externo.

Fêmures com pontos contrastantes. Mesepimeros, lados do metasterno e urosternitos com pontos profundos e abundantes.

Dimensões, em mm, holótipo macho/ parátipos fêmeas. Comprimento total 9,6/10,8-10,9; comprimento do protórax, 1,5/ 1,4-1,5; maior largura do protórax, 1,6/1,7-1,8; comprimento do élitro, 7,4/8,1-8,4; largura umeral, 2,0/2,1-2,2.

Material-tipo. Holótipo macho, COLÔMBIA, Boyacá: Iguaque (Quebrada Los Francos, 5 ${ }^{\circ} 25^{\prime} \mathrm{N}, 7^{\circ} 27^{\prime} \mathrm{W}, 2800 \mathrm{~m}$ ), 7-24.II.2001, P. Reina col., em malaise (IAHC). Parátipos: mesmos dados do holótipo, fêmea (IAHC); Boyacá: Iguaque (Serro Pan de Azúcar, $5^{\circ} 25^{\prime} \mathrm{N}$, $73^{\circ} 27^{\prime}$ W, 3300 m), fêmea, 16.IV.-2.V. 2001, P. Reina col., malaise (MZSP).

Discussão. Nyctonympha boyacana sp. nov. assemelhase a $N$. cribrata Thomson, 1868 (fig. 4); difere pelo antenômero III com menos da metade do comprimento do IV e pelo o espinho lateral do protórax pequeno. Em N. cribrata o antenômero III tem dois terços do comprimento do IV e o espinho lateral do protórax é diminuto. 


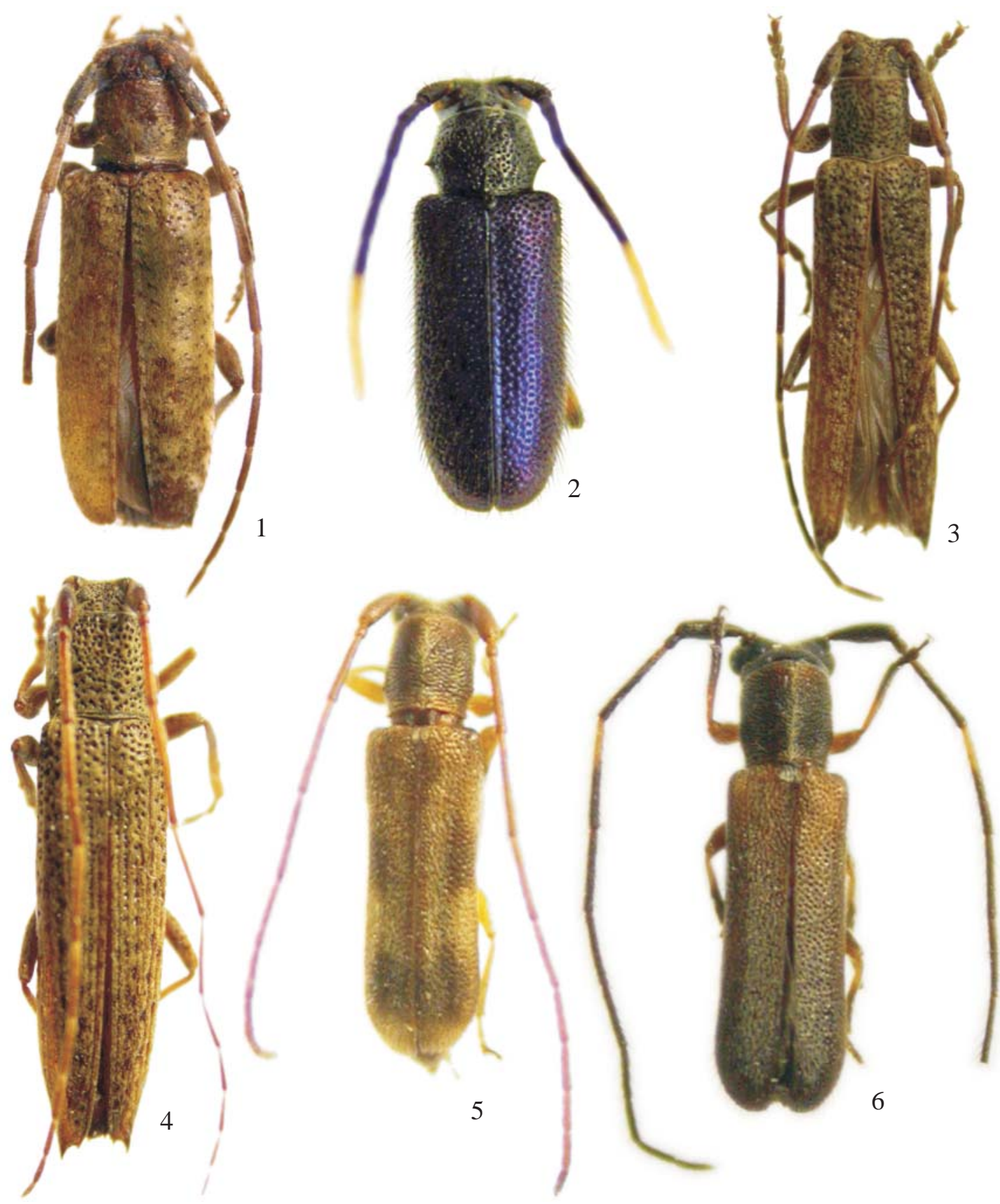

Figs. 1-6. 1, Drycothea gaucha sp. nov., holótipo macho, 10,0 mm; 2, Callia metallica sp. nov., holótipo macho, 6,0 mm; 3, Nyctonympha boyacana sp. nov., holótipo macho, $9,6 \mathrm{~mm}$; 4, Nyctonympha cribrata Thomson, 1868, macho, 12,4 mm; 5, Bactriola achira sp. nov. holótipo macho, 4,0 mm; 6, Bactriola antennata sp. nov. holótipo macho, 4,4 $\mathrm{mm}$.

Etimologia. Epíteto referente ao Departamento de Boyacá onde se situa a localidade-tipo.

\section{Bactriola achira sp. nov.}

(Fig. 5)

Cabeça com tegumento acastanhado revestido por pubescência amarelada. Vértice (50x) pontuado. Lobos oculares superiores tão afastados entre si quanto o dobro da largura de um lobo. Lobos oculares inferiores com o dobro do comprimento das genas. Antenas ultrapassam o ápice dos élitros na base do antenômero VIII. Escapo castanhoavermelhado. Demais antenômeros avermelhados com os dois últimos escurecidos ou não.

Protórax com lados desarmados ou com espículo no terço posterior mais evidente nos machos. Protórax com pubescência esbranquiçada menos em duas faixas longitudinais, largas, uma a cada lado do meio do pronoto.

Élitros com tegumento amarelado no quarto basal; restante da superfície, com tegumento acastanhado. Pubescência 
esbranquiçada reveste todo o élitro menos duas manchas acastanhadas em cada um: uma no meio e outra anteapical; essas manchas são menos evidentes quando os élitros têm tegumento predominantemente amarelado.

Mesepimeros pontuados. Metasterno com pêlos esbranquiçados. Fêmures com tegumento alaranjado, mais acastanhado nos lados. Tíbias acastanhadas com base alaranjada. Metatarsômero I tão longo quanto II+III. Urosternitos revestidos por pubescência mais amarelada.

Dimensões, em mm, macho/fêmea respectivamente. Comprimento total, 4,0/4,6; comprimento do protórax, 0,9/0,9; maior largura do protórax, 0,8/0,9; comprimento do élitro, 2,9/ 3,5; largura umeral, 1,0/1,1.

Material-tipo. Holótipo macho, BOLÍVIA, Santa Cruz: Achira (4$5 \mathrm{~km} \mathrm{~N}$, "road to Amboro"), 21-22.X.2000, Wappes \& Morris col. (MNKM). Parátipos: Santa Cruz, Província Florida ("Chaco above Achira”, Vicoquin área, $\left.18^{\circ} 07^{\prime} \mathrm{S}, 63^{\circ} 40^{\prime} \mathrm{W}, 1730 \mathrm{~m}\right)$, macho, 2 fêmeas, 22-25.I.2007, Wappes \& Lingafelter col. (MZSP, MCNZ, ACMS); 3 fêmeas, mesmos dados do holótipo (ACMS).

Discussão. Quando os exemplares de Bactriola achira $\mathbf{s p .}$ nov. têm manchas escuras nos élitros podem ser comparados com B. maculata Martins \& Galileo, 1992, mas as manchas são apenas duas em cada élitro e as antenas não têm a base dos flagelômeros esbranquiçada. Quando os exemplares têm élitros mais unicolores, Bactriola achira sp. nov. separa-se das demais espécies do gênero pelos élitros sem faixas longitudinais de pubescência esbranquiçada.

Etimologia. Nome específico alusivo à localidade-tipo.

\section{Bactriola antennata sp. nov.} (Fig. 6)

Cabeça com tegumento castanho-escuro, densamente pontuada. Tubérculos anteníferos muito distantes; região entre lobos superiores côncava; distância entre lobos maior que a largura de um lobo. Lobos oculares inferiores com o dobro do comprimento das genas. Antenas atingem os ápices dos élitros aproximadamente no ápice o antenômero VI; tegumento castanho-escuro, menos o terço basal do antenômero IV, avermelhado. Protórax castanho-avermelhado com uma área mais clara junto à margem anterior; pubescência esbranquiçada numa faixa longitudinal central; densamente pontuado. Escutelo inteiramente revestido por pubescência esbranquiçada. Élitros castanho-avermelhados com grande área centro-basal de tegumento amarelado; pubescência entre os pontos esbranquiçada, rala e mais concentrada numa faixa longitudinal, junto à sutura; pontuação densa. Face ventral do corpo com tegumento castanho-escuro, revestida por pubescência esbranquiçada, densa. Mesepisternos, metepisternos e lados do metasterno e dos urosternitos pontuados. Coxas avermelhadas. Profêmures avermelhados; base dos meso- e metafêmures avermelhada. Tíbias com a base amarelada.
Dimensões, em mm, holótipo macho/parátipo fêmea. Comprimento total, 4,4/4,7; comprimento do protórax, 1,0/1,1; maior largura do protórax, 0,9/1,0; comprimento do élitro, 3,1/ 3,5; largura umeral, 1,1/1,6.

Material-tipo. Holótipo macho, BOLÍVIA, Santa Cruz: Buena Vista (Hotel 4-6 km SSE, Hotel Flora \& Fauna), 21-25.XII.2003, R. Clarke col. (MNKM). Parátipo fêmea - mesmos dados do holótipo (ACMS).

Discussão. Separa-se Bactriola antennata sp. nov. de $B$. minuscula Fontes \& Martins, 1977 pela base do antenômero IV amarelada e pelas pernas bicolores. Em B. minuscula os antenômeros III a VI são castanhos com bases mais claras e as pernas são unicolores.

Etimologia. Epíteto alusivo ao antenômero IV com a base avermelhada.

Agradecimentos A Eleandro Moysés (MCNZ) pela execução das fotografias e tratamento das imagens. Aos curadores das instituições pelo empréstimo do material.

\section{REFERÊNCIAS}

Breuning, S. 1943. Novae species Cerambycidarum. XII. Folia Zoologica et Hydrobiologica 12: 12-66.

Breuning, S. 1974. Révision des Rhodopinini américains. Studia Entomologica 17: 1-210.

Lingafelter, S. W. \& E. H. Nearns. 2007. Five new species of longhorned beetles (Coleoptera: Cerambycidae) from the Dominican Republic in genera Ataxia Haldeman, Atimiola Bates, Drycothaea Thomson, Eburia Lepeletier \& Audinet S-Serville, and Hormathus Gahan. The Coleopterists Bulletin 61: 177-191.

Galileo, M. H. M. \& U. R. Martins. 1991. Revisão da tribo Calliini (Coleoptera, Cerambycidae, Lamiinae). Giornale Italiano di Entomologia 5: 243-262.

Galileo, M. H. M. \& U. R. Martins. 2002. Espécies novas e chave para as espécies de Callia (Coleoptera, Cerambycidae). Iheringia, Zoologia 92: 41-52.

Martins, U. R. \& M. H. M. Galileo. 1989. Sobre Falsamblesthiini (Coleoptera, Cerambycidae, Lamiinae). III. Subsídios para uma revisão. Revista Brasileira de Entomologia 33: 119-134.

Martins, U. R. \& M. H. M. Galileo. 1990. Notas sobre Calliini (Coleoptera, Cerambycidae, Lamiinae). IV. As espécies sulamericanas do gênero Drycothaea Thomson, 1868. Revista Brasileira de Entomologia 34: 607-613.

Martins, U. R. \& M. H. M. Galileo. 1992. Neotropical Cerambycidae (Coleoptera) primarily in the Canadian Museum of Nature, Ottawa. I. Falsamblesthiini (Lamiinae). Insecta Mundi 6: 101-108.

Monné, M. A. 2005. Catalogue of the Cerambycidae (Coleoptera) of the Neotropical Region. Part II. Subfamily Lamiinae. Zootaxa 1023: $1-760$.

Monné, M. A. \& F. T. Hovore. 2006. Cheklist of the Cerambycidae, or longhorned wood-boring beetles of the Western Hemisphere. Rancho Dominguez, BioQuip 394 p.

Tavakilian, G. L. 1991. Notas sinonímicas e novas combinações em longicórneos sul-americanos (Coleoptera, Cerambycidae). Revista Brasileira de Entomologia 35: 439-453.

Tavakilian, G. L. 1997. Nomenclatural changes, reinstatements, new combinations, and new synonymies among American Cerambycids (Coleoptera). Insecta Mundi 11: 129-139.

Zajciw, D. 1958. Descrição de uma nova espécie de Callia Serville, 1835, com chave para determinação das espécies brasileiras (Col., Cerambycidae). Revista Brasileira de Entomologia 8: 55-58. 